Hai Nguyen Tran, Fu-Chuang Huang, Chung-Kung Lee and Huan-Ping Chao*

\title{
Activated carbon derived from spherical hydrochar functionalized with triethylenetetramine: synthesis, characterizations, and adsorption application
}

DOI 10.1515/gps-2016-0178

Received October 15, 2016; accepted January 2, 2017; previously published online March 6, 2017
Keywords: activated carbon; dye; glucose; heavy metal; hydrochar; triethylenetetramine.

\section{Introduction}

Activated carbon (AC), with its exceptionally large specific surface area, high pore volume, well-developed internal porous structure, and abundant surface functional groups (polar characters), has been widely applied in various industrial processes. In water treatment, ACs are considered effective adsorbents for the removal of various organic contaminants. According to an industry market research report [1], the global demand for AC is estimated to increase $8.1 \%$ per year, and be up to 2.1 million metric tons by 2018. Nevertheless, the high cost of commercial ACs restricts their large-scale use in industries.

Notably, the morphology of AC plays a key role in its application; various conformations comprise powdered and granular AC, AC fibers, carbon monoliths, carbon hollow spheres, carbon nanotubes, and, carbon spheres [2]. Spherical carbon can be obtained through hydrothermal carbonization of diverse organic materials (polyvinylpyrrolidone, sucrose, xylose, fructose, furfural, glucose, starch, saccharose, and cellulose) in a controlled temperature autoclave $\left(150-350^{\circ} \mathrm{C}\right)$ for $2-48 \mathrm{~h}$ at a specific pressure for producing hydrochar spherical microparticles [3-6]. Hydrochars have been commonly tailored for manufacturing ACs with desired characteristics because of the unique attributions of hydrochar - namely a high density of oxygenated functional groups and a low degree of condensation and impurity [3]. Compared with other ACs, spherical ACs exhibit several enhanced characteristics such as high wear resistance, high mechanical strength, superior adsorption, high purity, low ash content, smooth surface, low pressure drop, high bulk density, high micropore volume, and controllable pore size distribution $[2,3]$.

D-glucose (a simple carbohydrate) is the most abundant sugar unit in biomass, and it is the major product

\footnotetext{
*Corresponding author: Huan-Ping Chao, Department of Environmental Engineering, Chung Yuan Christian University, Chungli 32023, Taiwan, e-mail: hpchao@cycu.edu.tw Hai Nguyen Tran: Department of Civil Engineering, Chung Yuan Christian University, Chungli 32023, Taiwan; and Department of Environmental Engineering, Chung Yuan Christian University, Chungli 32023, Taiwan

Fu-Chuang Huang: Department of Environmental Technology and Management, Taoyuan Innovation Institute of Technology, Chung-Li, 32091, Taiwan

Chung-Kung Lee: Department of Environmental Engineering, Vanung University, Chung-Li, 32061, Taiwan
} 
of lignocellulosic biomass acid hydrolysis. Therefore, D-glucose is the most used precursor to produce hydrothermal carbonization [4]. A review of the extant literature revealed that the adsorption capacity of glucose-derived carbon spheres is enhanced by modifying their surfaces with various surfactants. For example, Demir-Cakan and others [7] prepared carbonaceous materials (hydrochar) through the hydrothermal carbonization of glucose in the presence of acrylic acid, and they concluded that carboxylate-rich absorbents were successfully employed for the removal of $\mathrm{Cd}^{2+}$ and $\mathrm{Pb}^{2+}$ from water. Wang and coworkers [8] reported on a one-step hydrothermal preparation of amino-functionalized carbon spheres (hydrochar) by mixing a glucoseammonia solution at low temperature to improve their adsorption performance toward $\mathrm{Cr}(\mathrm{VI})$.

Various nitrogen sources, derived from nitrogen gas, ammonia, ammonia gas, amines, urea, pyridine, acetonitrile, melamine, dimethylformamide, 2-amino-4,6-dichloro-s-triazine, benzylamine, triethylenetetramine (TETA), ethylenediamine, and polyazomethineamide, have been used for synthesizing nitrogen-doped porous carbons [8-13]. Of these, TETA has been widely applied as an effective cationic surfactant to modify an adsorbent's surface; for example the effective adsorption of $\mathrm{Cu}^{2+}, \mathrm{Cd}^{2+}$, and $\mathrm{Pb}^{2+}$ from aqueous solutions by both succinylated twice-mercerized sugarcane bagasse and succinylated mercerized cellulose modified with TETA has been proposed by [12, 13]. Karnitz and colleagues [10] also compared the adsorption capacities of $\mathrm{Cu}^{2+}, \mathrm{Cd}^{2+}$, and $\mathrm{Pb}^{2+}$ from aqueous systems by sugarcane bagasse chemically modified with the polyamines ethylenediamine and TETA. In addition, Barsanescu and colleagues [14] investigated the effectiveness of using acrylic copolymer prepared from organic matrices with distinct crosslinking degrees, followed by ethylenediamine and TETA functionalization on the surface to remove $\mathrm{Zn}^{2+}$ ions. However, the characterizations of TETA-modified spherical and activated carbons derived from glucose and the efficiency of these adsorbents toward the removal of organic and inorganic contaminants have not been examined and reported elsewhere.

The current study synthesized a TETA-modified adsorbent to determine the adsorption of inorganic and organic compounds from aqueous solutions. Glucosederived hydrochar (GH) samples, functionalized with various TETA concentrations $(1 \%-5 \%)$, were prepared through hydrothermal carbonization of the glucoseTETA mixture, and they were subsequently used as the precursors to produce glucose-AC (GACs). The GAC samples with nitrogen groups on their surface were synthesized through a $\mathrm{NaOH}$ chemical activation of the GH samples; GH and GAC samples without TETA modification were also simultaneously prepared. In addition, the basic properties of the adsorbents were examined using several techniques (i.e. Brunauer-Emmett-Teller [BET] surface area, Fourier transform infrared [FTIR], and scanning electron microcopy-energy dispersive X-ray [SEM-EDX] analyses). Furthermore, the adsorption behaviors of GHs and GACs with and without a TETAfunctionalized surface for two heavy metals $\left(\mathrm{Pb}^{2+}\right.$ and $\mathrm{Cu}^{2+}$ ), phenol, a basic dye (methylene green 5 [MG5]), and an acid dye (acid red 1 [AR1]) were conducted in batch experiments.

\section{Materials and methods}

\subsection{Preparation of adsorbents}

The synthesis processes of carbonaceous adsorbents with and without surface modification are illustrated in Figure 1. First, a mixture of glucose and TETA powders (purchased from Merck) was completely dissolved in $150 \mathrm{ml}$ of distilled water and then transferred into a 200$\mathrm{ml}$ Teflon-lined autoclave. Mass ratios of glucose and TETA ranging from $1 \%$ to $5 \%$ were used for the modification. After a 48 -h hydrothermal process at $190^{\circ} \mathrm{C}$, the remaining brown precipitate (hydrochar) particles were separated using vacuum filtration, washed repeatedly with a 95\% alcohol solution, and then washed in the distilled water until the $\mathrm{pH}$ of the filtrate reached approximately 7.0. The hydrochar samples were then collected and dried in an oven at $105^{\circ} \mathrm{C}$ for $24 \mathrm{~h}$. For convenience, the GH samples modified with TETA were labeled

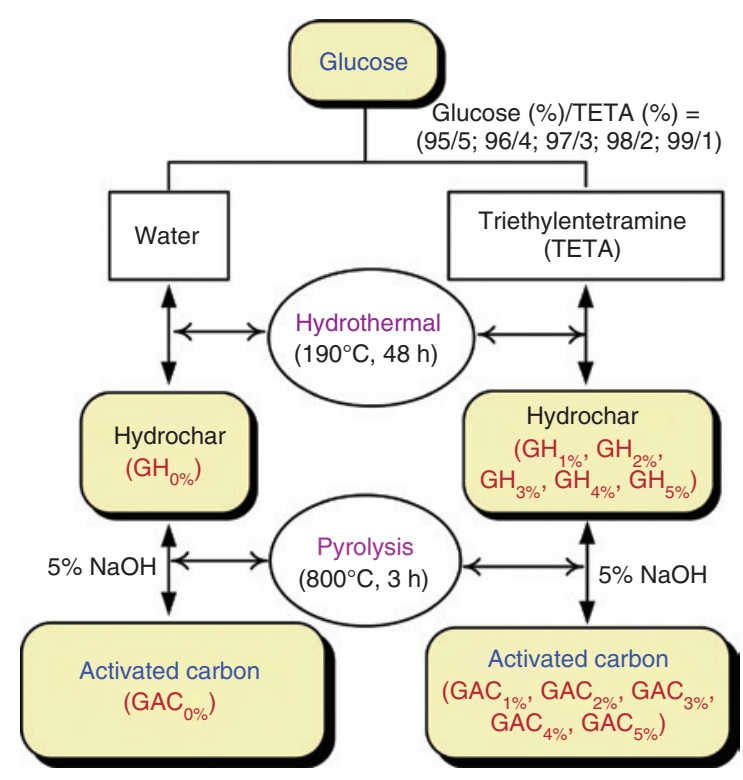

Figure 1: Schematic illustration of the preparation procedure for the adsorbents. 
$\mathrm{GH}_{5 \%}, \mathrm{GH}_{4 \%}, \mathrm{GH}_{3 \%}, \mathrm{GH}_{2 \%}$, and $\mathrm{GH}_{1 \%}$, according to the ratio of TETA to glucose. A GH sample without TETA $\left(\mathrm{GH}_{0 \%}\right)$ was synthesized under the same conditions.

The AC was prepared by first impregnating approximately $10 \mathrm{~g}$ of the hydrochar sample with $100 \mathrm{ml}$ of $\mathrm{NaOH}$ solution (5\%). Next, the mixture of hydrochar and $\mathrm{NaOH}$ was dried in an oven at $105^{\circ} \mathrm{C}$ until the solution completely evaporated. The pyrolysis process was conducted in a column-type stainless steel tube in an inert atmosphere; subsequently, the tube was heated to $800^{\circ} \mathrm{C}$ at a heating rate of $5^{\circ} \mathrm{C} / \mathrm{min}$ and the temperature was maintained for $3 \mathrm{~h}$ under a $\mathrm{N}_{2}$ flow rate of $100 \mathrm{ml} / \mathrm{min}$. The GACs were washed with alcohol and the distilled water until the $\mathrm{pH}$ of the filtrate was approximately 7.0, and then they were dried in an oven at $105^{\circ} \mathrm{C}$ for $24 \mathrm{~h}$. The final GAC samples were labeled according to their precursors (i.e. $\mathrm{GAC}_{5 \%}, \mathrm{GAC}_{4 \%}$, $\mathrm{GAC}_{3 \%}, \mathrm{GAC}_{2 \%}, \mathrm{GAC}_{1 \%}$, and $\left.\mathrm{GAC}_{0 \%}\right)$.

\subsection{Adsorbent characterization}

The textural properties of the GACs were obtained from a conventional analysis of nitrogen adsorption-desorption isotherms, which were measured at $77 \mathrm{~K}$ by a sorptometer (Micromeritics ASAP 2020). FTIR spectroscopy (FT/IR-6600 Jasco) was then performed to detect the functional groups present on the adsorbent surface, and the adsorbent particles mixed with $\mathrm{KBr}$ were subsequently pelleted. Finally, the morphology and element composition of the adsorbents were examined using SEM (S-3000N, Hitachi) at $10 \mathrm{kV}$ and EDX spectroscopy (EDX), respectively.

\subsection{Adsorptive isotherm experiment}

Two metal ions $\left(\mathrm{Pb}^{2+}\right.$ and $\left.\mathrm{Cu}^{2+}\right)$ and three organic compounds (phenol, AR1, and MG5) were selected as typical adsorbates to determine the adsorption characteristics of the GH and GAC samples. The chemical structures and basic properties of phenol, MG5, and AR1 are represented in Figure S1, and the basic and ionic properties of $\mathrm{Cu}^{2+}$ and $\mathrm{Pb}^{2+}$ are summarized in Table $\mathrm{S} 1$.

To avoid the precipitation of ionic salts and effect of dissociation on the selected organic solutes at high $\mathrm{pH}$ values, the initial $\mathrm{pH}$ values of the solutions were adjusted to $5.0 \pm 0.1$. Approximately $0.2 \mathrm{~g}$ of the adsorbent was subsequently added to $50 \mathrm{ml}$ of aqueous adsorbate solution in a Teflon centrifuge tube. To prevent adsorption competition, only a single adsorbate was added in the centrifuge tube. The centrifuge tubes were then placed in a reciprocating shaker with $180 \mathrm{rpm}$ and equilibrated for $48 \mathrm{~h}$ at $30^{\circ} \mathrm{C}$. After the completion of the adsorption process, each solution was centrifuged for $30 \mathrm{~min}$ and strained through a $0.2-\mu \mathrm{m}$ filter. The concentrations of phenol, MG5, and AR1 were determined using ultraviolent-visible spectrophotometry (Genesys 10 UV-Vis; Thermo Scientific) at maximum wavelengths of $265 \mathrm{~nm}, 655 \mathrm{~nm}$, and $530 \mathrm{~nm}$, respectively. Atomic absorption spectrometry (Avanta, $\mathrm{GBC}$ ) was used to determine the concentration of $\mathrm{Pb}^{2+}$ and $\mathrm{Cu}^{2+}$ ions.

Each experiment was performed in duplicate, and blank samples without the adsorbent were also conducted simultaneously. If the bias of the repeated experiment exceeded $15 \%$, a triplicate run was performed. All chemicals used in this study were of analytical reagent grade.

\section{Results and discussion}

\subsection{Characterization of adsorbents}

\subsubsection{Textural properties}

Figure S2 depicts the variation of $\mathrm{N}_{2}$ adsorption-desorption isotherms for GACs synthesized with various glucose-TETA ratios, clearly indicating that the adsorption isotherms of all the GACs generated hysteresis loops. Isotherms are typically characterized by mesopores and macropores, with a small external surface area [15]; moreover, a wideknee hysteresis loop was present in both the adsorption and desorption isotherms, appearing in the multilayer range of physical adsorption isotherms. According to the nomenclature of the International Union of Pure and Applied Chemistry, porous carbon materials exhibit an H4-type hysteresis loop, which is associated with narrow, slit-like pores. In addition, the AC sample without TETA $\left(\mathrm{GAC}_{0 \%}\right)$ exhibits a relatively higher non-micropore volume $\left(0.167 \mathrm{~cm}^{3} / \mathrm{g}\right)$ than the ACs samples modified with TETA $\left(\mathrm{GAC}_{1 \%-5 \%} ; 0.033-0.108 \mathrm{~cm}^{3} / \mathrm{g}\right)$. The reason is ascribed to TETA fills in the pores. The addition of TETA can alter the surface properties of $\mathrm{GAC}_{1 \%-5 \%}$.

Table 1 provides a summary of the corresponding textural parameters of the GACs. Increasing the TETA ratios resulted in a decreased surface area $\left(S_{\mathrm{BET}}\right)$, non-micropore volume, and total pore volume, but an increase of the micropore volume. Furthermore, the average pore width decreased as the ratio of TETA increased, indicating that the GAC pore size was determined by the amount of TETA in the sample. As expected, the average pore size of GACs was a function of the proportion of the non-micropore (mesopore and macropore) volume.

\subsubsection{Morphological properties}

The morphologies of $\mathrm{GH}_{0 \%}$ and $\mathrm{GAC}_{0 \%}$ are portrayed in Figure 2. The SEM images of both $\mathrm{GH}_{0 \%}$ and $\mathrm{GAC}_{0 \%}$ reveal interconnected spheres with relatively uniform sizes, smooth outer surfaces, and regular spherical shapes. According to a study by Sevilla and Fuertes [17], the formation of a carbon-rich solid through the hydrothermal carbonization of glucose is attributed to dehydration, condensation, or polymerization and aromatization reactions. In short, the carbon-rich hydrochar particle consists of two parts: a hydrophobic core comprising a highly aromatic nucleus, and a hydrophilic shell comprising a high 
Table 1: Textural parameters of the glucose activated carbon (ACs) and commercial AC.

\begin{tabular}{|c|c|c|c|c|c|c|c|}
\hline & $\mathrm{GAC}_{5 \%}$ & $\mathrm{GAC}_{4 \%}$ & $\mathrm{GAC}_{3 \%}$ & GAC $_{2 \%}$ & $\mathrm{GAC}_{1 \%}$ & $\mathrm{GAC}_{0 \%}$ & $\mathrm{CAC}^{\mathrm{a}}$ \\
\hline BET surface area $\left(\mathrm{m}^{2} / \mathrm{g}\right)$ & 260 & 313 & 256 & 288 & 233 & 335 & 768 \\
\hline Langmuir surface area $\left(\mathrm{m}^{2} / \mathrm{g}\right)$ & 311 & 402 & 327 & 364 & 295 & 418 & - \\
\hline External surface area $\left(\mathrm{m}^{2} / \mathrm{g}\right)$ & 69 & 113 & 115 & 135 & 151 & 195 & - \\
\hline Micropore surface area $\left(\mathrm{m}^{2} / \mathrm{g}\right)$ & 191 & 200 & 141 & 153 & 82 & 140 & - \\
\hline Total pore volume $\left(\mathrm{cm}^{3} / \mathrm{g}\right)$ & 0.110 & 0.144 & 0.149 & 0.169 & 0.137 & 0.217 & 0.43 \\
\hline Micropore volume $\left(\mathrm{cm}^{3} / \mathrm{g}\right)$ & 0.077 & 0.088 & 0.058 & 0.061 & 0.029 & 0.050 & 0.21 \\
\hline Non-micropore volume $\left(\mathrm{cm}^{3} / \mathrm{g}\right)$ & 0.033 & 0.056 & 0.091 & 0.108 & 0.108 & 0.167 & 0.22 \\
\hline Micropore/total pore volume (\%) & 70.27 & 60.88 & 38.78 & 36.25 & 20.98 & 22.98 & 48.84 \\
\hline Average pore width (nm) & 1.692 & 1.843 & 2.332 & 2.343 & 2.354 & 2.588 & 1.63 \\
\hline
\end{tabular}

Total pore volume $=$ sum of micropore volume and non-micropore volume.

aThe experimental data were published in [16].

BET, Brunauer-Emmett-Teller; CAC, commercial activated carbon ; GAC, glucose-activated carbon.
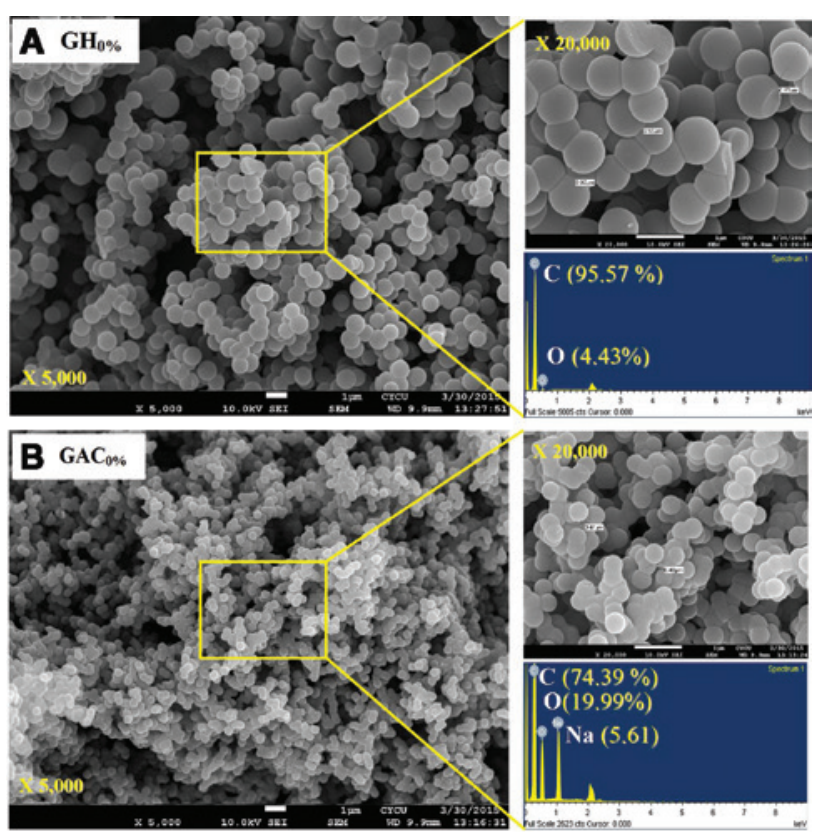

Figure 2: Scanning electron microcopy-energy dispersive X-ray (SEM-EDX) spectra of the (A) glucose-derived hydrochar $(\mathrm{GH})_{0 \%}$ and (B) glucose-activated carbon $(\mathrm{GAC})_{0 \%}$ samples.

concentration of reactive oxygen functional groups such as hydroxyl-phenolic, carbonyl, or carboxyl [17, 18].

Figure 2 also indicates that $\mathrm{GH}_{0 \%}$ exhibited a higher average diameter $(0.82-0.92 \mu \mathrm{m})$ than that of $\mathrm{GAC}_{0 \%}(0.38-$ $0.43 \mu \mathrm{m})$, suggesting that the size of carbon spheres is narrowly affected by the chemical activation process; the SEM results also revealed that the spherical morphology of $\mathrm{GAC}_{0 \%}$ possesses a similar particle size. This means that the regular shape of carbon spheres was still maintained after chemical activation. Interconnected particle properties of $\mathrm{GH}_{0 \%}$ and $\mathrm{GAC}_{0 \%}$ afforded more facile adsorbent separation from aqueous solutions (i.e. filtration with a microfilter) because of the overall increase in particle size [19].
As displayed in Figure 3, there were substantial changes to the surface morphology of the samples following TETA modification. The samples initially possessed extremely rough surfaces, and the results demonstrated that TETA was successfully grafted onto the surface of GAC during our experiment. Moreover, the morphologies of $\mathrm{GH}_{1 \%}$ and $\mathrm{GAC}_{1 \%}$ were nearly identical, again confirming that chemical activation with $\mathrm{NaOH}$ did not cause noticeable alterations to the morphology of GACs. Therefore, $\mathrm{NaOH}$ activation only modified the surface of GACs, without affecting the morphology and the bulk carbon core. This conclusion is consistent with findings in the extant literature [20].
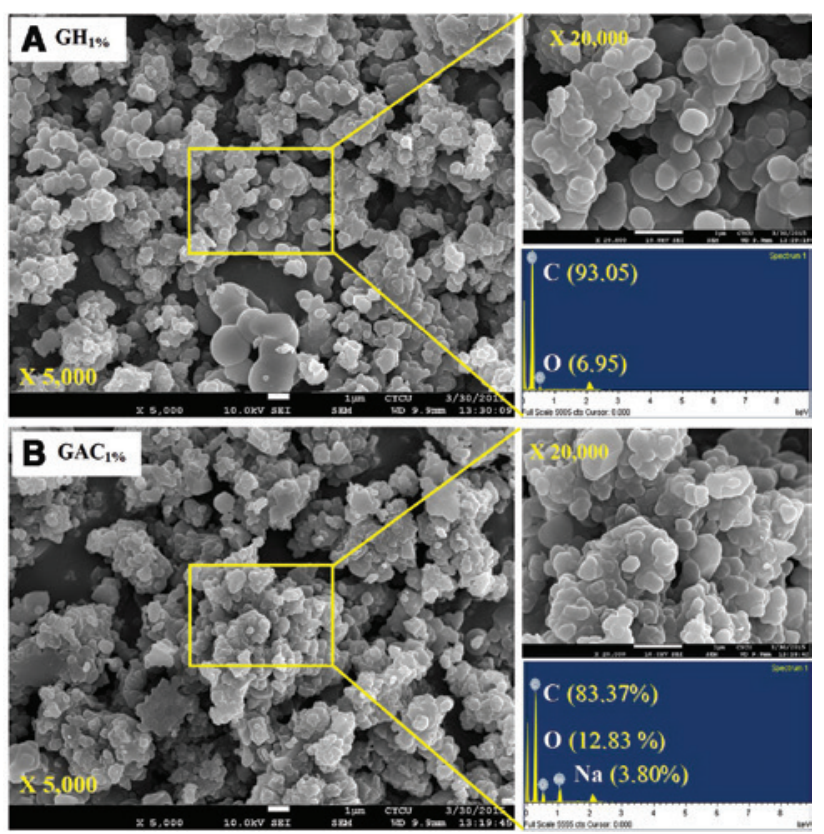

Figure 3: Scanning electron microcopy-energy dispersive $\mathrm{X}$-ray (SEM-EDX) spectra of the (A) glucose-derived hydrochar $(\mathrm{GH})_{1 \%}$ and (B) glucose-activated carbon $(\mathrm{GAC})_{1 \%}$ samples. 
The EDX spectra displayed in Figures 2 and 3 reveal that elements containing $\mathrm{C}$ and $\mathrm{O}$ are primary elements; for example, hydochar is a carbon-rich solid that is approximately $93-96 \%$ carbon. The higher percentage of $\mathrm{Na}$ in the GAC samples indicated that the presence of neither the functional hydrolyzed-carboxylic acid group (-COO- $\mathrm{Na}^{+}$or $-\mathrm{COO}^{-}$under aqueous conditions) nor the functional hydrolyzed-phenolic group $\left(-\mathrm{O}-\mathrm{Na}^{+}\right.$or $-\mathrm{O}^{-}$ under aqueous conditions) was strongly correlated with the high cationic affinity of the GAC samples [19]. The presence of carboxylic and phenolic groups on the surface of GHs and GACs was additionally confirmed by the FTIR analysis results (Figure 4). Moreover, the higher percentage of oxygen in the GAC samples suggests that the GAC samples had more acidic functional groups than the GH samples. Noticeably, the percentage of $\mathrm{N}$ element is lower than the detection limitation because of low impregnation of TETA (only 1\%); therefore it cannot be identified in EDX analysis.

\subsubsection{Functional group characterizations}

The functional groups of $\mathrm{GAC}_{0 \%}$ and its precursor $\left(\mathrm{GH}_{0 \%}\right)$ were identified using FTIR (Figure S3). For the $\mathrm{GH}_{0 \%}$ sample, two peaks identified at $1965 \mathrm{~cm}^{-1}$ and $1200 \mathrm{~cm}^{-1}$ were involved in the stretching of the $\mathrm{C}=0$ and $\mathrm{C}-\mathrm{O}$ bonds in "pristine" carboxyl groups, respectively (Figure S3). Furthermore, the band at $1600 \mathrm{~cm}^{-1}$ is related to the aromatic $\mathrm{C}=\mathrm{C}$ ring stretching motion, and the band at $3400 \mathrm{~cm}^{-1}$ confirms the presence of oxygen

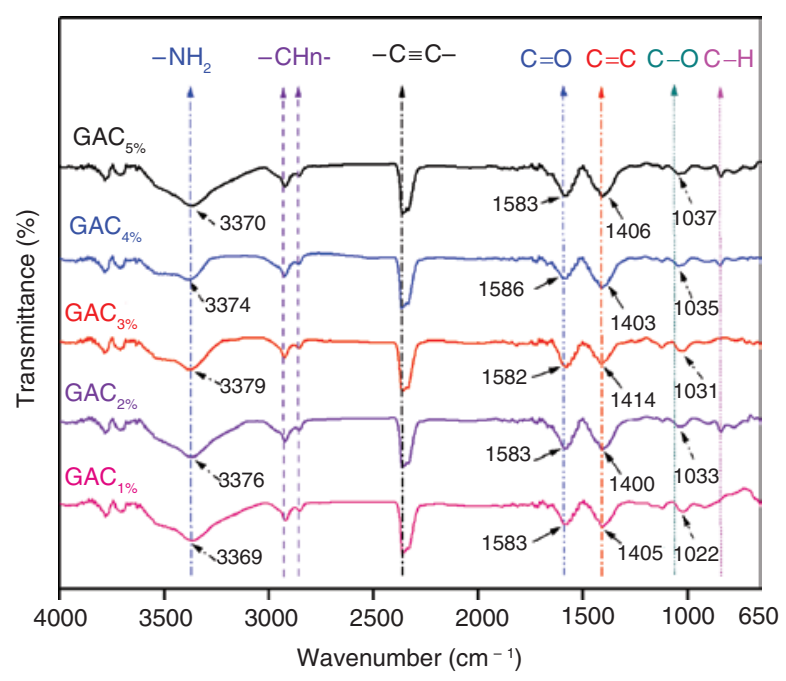

Figure 4: Fourier transform infrared (FTIR) spectra of the glucose activated carbon (AC) samples at various triethylenetetramine (TETA) impregnation ratios. in hydrochar in the form of $-\mathrm{OH}$. The presence of aromatic $\mathrm{C}-\mathrm{H}$ out-of-plane bending vibrations is evident by the peak at $798 \mathrm{~cm}^{-1}$ (including aldol condensation and dehydration) [7]. As researchers have previously noted, the appearance of $\mathrm{C}=\mathrm{O}$ groups on the surface of glucose hydrochar is due to the dehydration of equatorial hydroxyl groups $[3,17]$.

The FTIR spectrum of $\mathrm{GAC}_{0 \%}$ (Figure S3) revealed similar peaks to those of $\mathrm{GH}_{0 \%}$ (i.e. $\mathrm{C}=\mathrm{O}, \mathrm{C}=\mathrm{C}, \mathrm{C}-\mathrm{O},-\mathrm{OH}$, and $\mathrm{C}-\mathrm{H}$ ). New vibration bands at $2919 \mathrm{~cm}^{-1}$ and $2850 \mathrm{~cm}^{-1}$ corresponded to asymmetrical and symmetrical $\mathrm{C}-\mathrm{H}$, respectively. The peaks related to the carboxyl groups in $\mathrm{GAC}_{0 \%}$ noticeably shifted toward lower wavelengths after the sample underwent chemical activation with $\mathrm{NaOH}$, compared with the peaks in $\mathrm{GH}_{0 \%}$ groups; specifically, the $\mathrm{C}=\mathrm{O}$ and $\mathrm{C}-\mathrm{O}$ peaks decreased from $1659 \mathrm{~cm}^{-1}$ to $1590 \mathrm{~cm}^{-1}$ and from $1200 \mathrm{~cm}^{-1}$ to $1030 \mathrm{~cm}^{-1}$, respectively. In addition, the marked increase in band intensity at $3390 \mathrm{~cm}^{-1}$ indicated that new $-\mathrm{OH}$ groups can form during chemical activation.

Qualitative information on the functional groups present on the TETA-modified $\mathrm{GAC}_{\mathrm{x} \%}$ surfaces and their spectroscopic assignments is displayed in Figure 4. The bands observed at approximately $3370 \mathrm{~cm}^{-1}$ are attributed to the stretching vibrations of the primary amine $\left(-\mathrm{NH}_{2}\right)$ group overlapped with the stretching band in the hydroxyl groups $(\mathrm{O}-\mathrm{H})$ centered at $3400-3500 \mathrm{~cm}^{-1}$ [21]. The bands found in the $2800-3000 \mathrm{~cm}^{-1}$ range belong to asymmetrical and symmetrical $\mathrm{C}-\mathrm{H}$ stretching vibrations of the methyl $\left(-\mathrm{CH}_{3}-\right)$ and methylene $\left(-\mathrm{CH}_{2}-\right)$ groups. The presence of a carbon-carbon triple bone $(\mathrm{C} \equiv \mathrm{C})$ in disubstituted alkynes can also be inferred from the bands in the range of $2250-2400 \mathrm{~cm}^{-1}$. The sharp peaks recognized between $1500 \mathrm{~cm}^{-1}$ and $1690 \mathrm{~cm}^{-1}$ are attributed to the stretching vibration of $\mathrm{C}=\mathrm{O}$ in the secondary amide group [22] or $-\mathrm{NH}_{2}$ scissor frequencies [21, 23]. The $\mathrm{C}=\mathrm{O}$ bond in the carboxyl group clearly shifted to lower wavelengths (i.e. deformation vibrations) after reaction with TETA. Specifically, the $\mathrm{C}=\mathrm{O}$ bond in the pristine carboxyl group peaked at $1590 \mathrm{~cm}^{-1}$ (Figure S3), but after TETA modification, the peak decreased to approximately $1580 \mathrm{~cm}^{-1}$ (Figure 4). The bands observed at around $1400 \mathrm{~cm}^{-1}$ also reveal the aromatization $(\mathrm{C}=\mathrm{C})$ of the $\mathrm{GAC}_{\mathrm{x} \%}$ samples. Finally, the bands located between $960 \mathrm{~cm}^{-1}$ and $1130 \mathrm{~cm}^{-1}$ are characteristic of stretching $\mathrm{C}-\mathrm{O}$ groups; the low intensity in these bands confirms the existence of strong reactions between pristine carboxyl groups and TETA. The reaction between the carboxyl groups and TETA, which converts the $\mathrm{C}=\mathrm{O}$ in carboxyl groups into $\mathrm{C}=\mathrm{O}$ in the amide groups, was introduced by Brady and Duncan [24] and occurs as follows: 


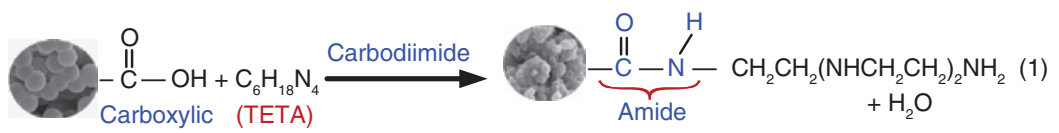

\subsection{Adsorption isotherms}

In this study, the Langmuir model [Eq. (2)] and Freundlich model [Eq. (3)] were applied to describe the adsorptive behavior of the contaminants on the synthesized adsorbents:

$$
\begin{gathered}
q_{\mathrm{e}}=\frac{Q_{\mathrm{max}}^{0} K_{\mathrm{L}} C_{\mathrm{e}}}{1+K_{\mathrm{L}} C_{\mathrm{e}}} \\
q_{\mathrm{e}}=K_{\mathrm{F}} C_{\mathrm{e}}^{1 / n}
\end{gathered}
$$

where $q_{\mathrm{e}}(\mathrm{mg} / \mathrm{g})$ is the amount of adsorbate uptake at equilibrium (which was calculated from the mass balance equation), $C_{\mathrm{e}}(\mathrm{mg} / \mathrm{l})$ is the adsorbate concentration at equilibrium, $Q^{o}{ }_{\text {max }}(\mathrm{mg} / \mathrm{g})$ is the maximum saturated monolayer adsorption capacity of the adsorbent, $K_{\mathrm{L}}(\mathrm{l} / \mathrm{mg})$ is the Langmuir constant related to the affinity between an adsorbent and adsorbate, $K_{\mathrm{F}}(\mathrm{mg} / \mathrm{g}) /(\mathrm{mg} / \mathrm{l})^{1 / \mathrm{n}}$ is the Freundlich constant (which characterizes adsorption strength), and $1 / n$ (dimensionless; $0<n<10$ ) is a Freundlich intensity parameter (which indicates the magnitude of the adsorption driving force or surface heterogeneity).

The coefficient of determination $\left(R^{2}\right)$ of the nonlinear optimization method was computed using the following equation:

$$
\begin{aligned}
R^{2} & =1-\frac{\sum\left(q_{\mathrm{e}, \mathrm{exp}}-q_{\mathrm{e}, \mathrm{cal}}\right)^{2}}{\sum\left(q_{\mathrm{e}, \text { exp }}-q_{\mathrm{e}, \text { mean }}\right)^{2}} \\
& =\frac{\sum\left(q_{\mathrm{e}, \mathrm{cal}}-q_{\mathrm{e}, \text { mean }}\right)^{2}}{\sum\left(q_{\mathrm{e}, \mathrm{cal}}-q_{\mathrm{e}, \text { mean }}\right)^{2}+\sum\left(q_{\mathrm{e}, \mathrm{cal}}-q_{\mathrm{e}, \mathrm{exp}}\right)^{2}}
\end{aligned}
$$

where $q_{\mathrm{e} \text { exp }}(\mathrm{mg} / \mathrm{g})$ is the amount of adsorbate adsorbed at equilibrium obtained from the experiment; $q_{\mathrm{e}, \text { cal }}(\mathrm{mg} / \mathrm{g})$ is the amount of adsorbate uptake determined from the model after using the Solver add-in, and $q_{\mathrm{e}, \text { mean }}(\mathrm{mg} / \mathrm{g})$ is the mean value of $q_{\mathrm{e} \text { exp }}$ [25].

The Langmuir and Freundlich parameters are described in Tables S2-S6. Notably, the determination coefficients $\left(R^{2}\right)$ of the Langmuir model were higher than those of the Freundlich in most of the cases, indicating that the adsorption characteristics of the contaminants in the GH and GAC samples were adequately described by the Langmuir model.

\subsubsection{Adsorption isotherms for lead and copper}

Figures 5 and 6 show the adsorption isotherms of $\mathrm{Pb}^{2+}$ and $\mathrm{Cu}^{2+}$ ions on the hydrochars and ACs at various impregnation ratios of TETA and glucose. After the surfaces of the GH samples were modified with TETA, the $Q^{o}{ }_{\text {max }}$ values of $\mathrm{Pb}^{2+}$ and $\mathrm{Cu}^{2+}$ increased by $29 \%-114 \%$ and $15 \%-245 \%$, respectively. This result indicates that the TETA surfactant effectively bonds metal ions. The maximum adsorptive amounts of the $\mathrm{Pb}^{2+}$ ions were ordered as follows: $\mathrm{GH}_{1 \%}>\mathrm{G}$ $\mathrm{H}_{3 \%}>\mathrm{GH}_{2 \%}>\mathrm{GH}_{4 \%}>\mathrm{GH}_{5 \%}>\mathrm{GH}_{0 \%}$. Conversely, the ordering of $\mathrm{Cu}^{2+}$ adsorption was $\mathrm{GH}_{5 \%}>\mathrm{GH}_{1 \%} \approx \mathrm{GH}_{3 \%}>\mathrm{GH}_{2 \%}>\mathrm{GH}_{0 \%}$.
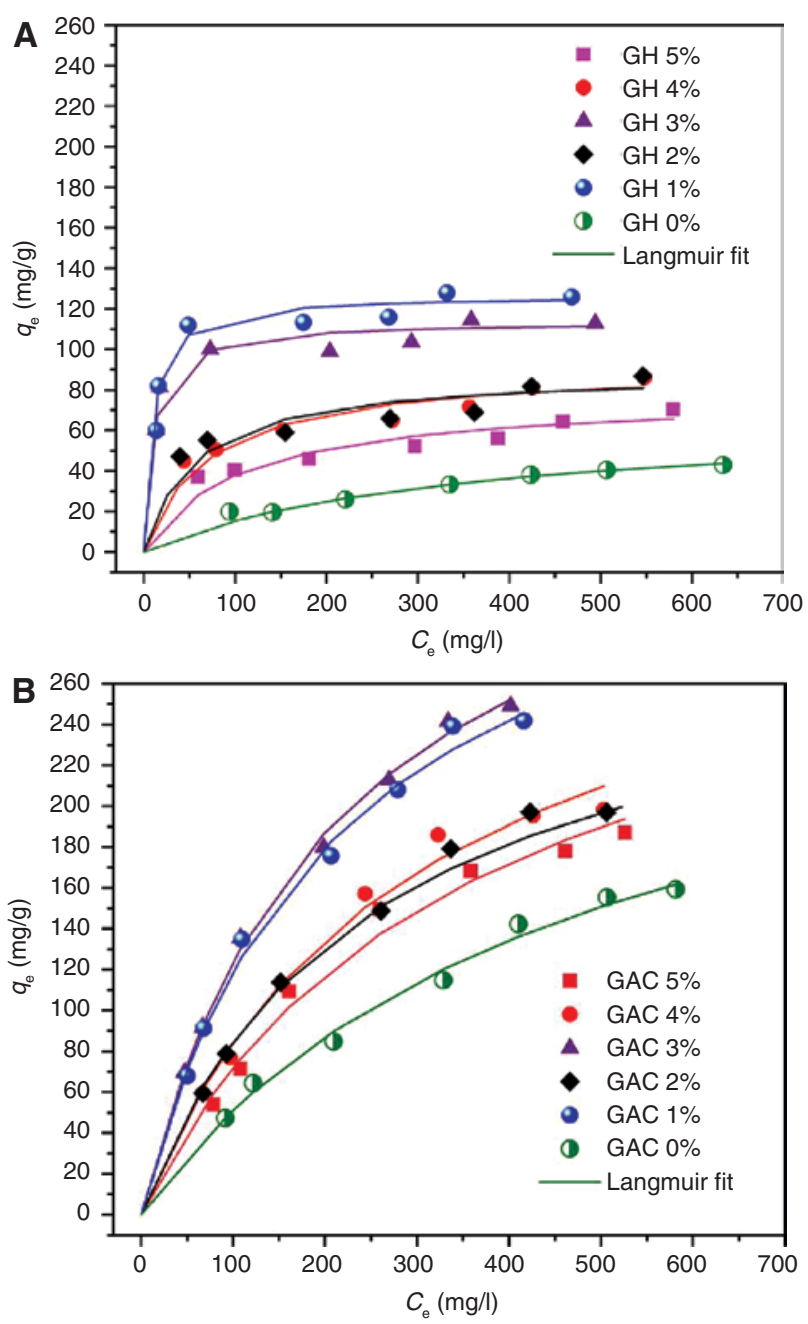

Figure 5: Adsorption isotherms of $\mathrm{Pb}^{2+}$ ions by various (A) glucose hydrochar and (B) activated carbon (AC) samples. 

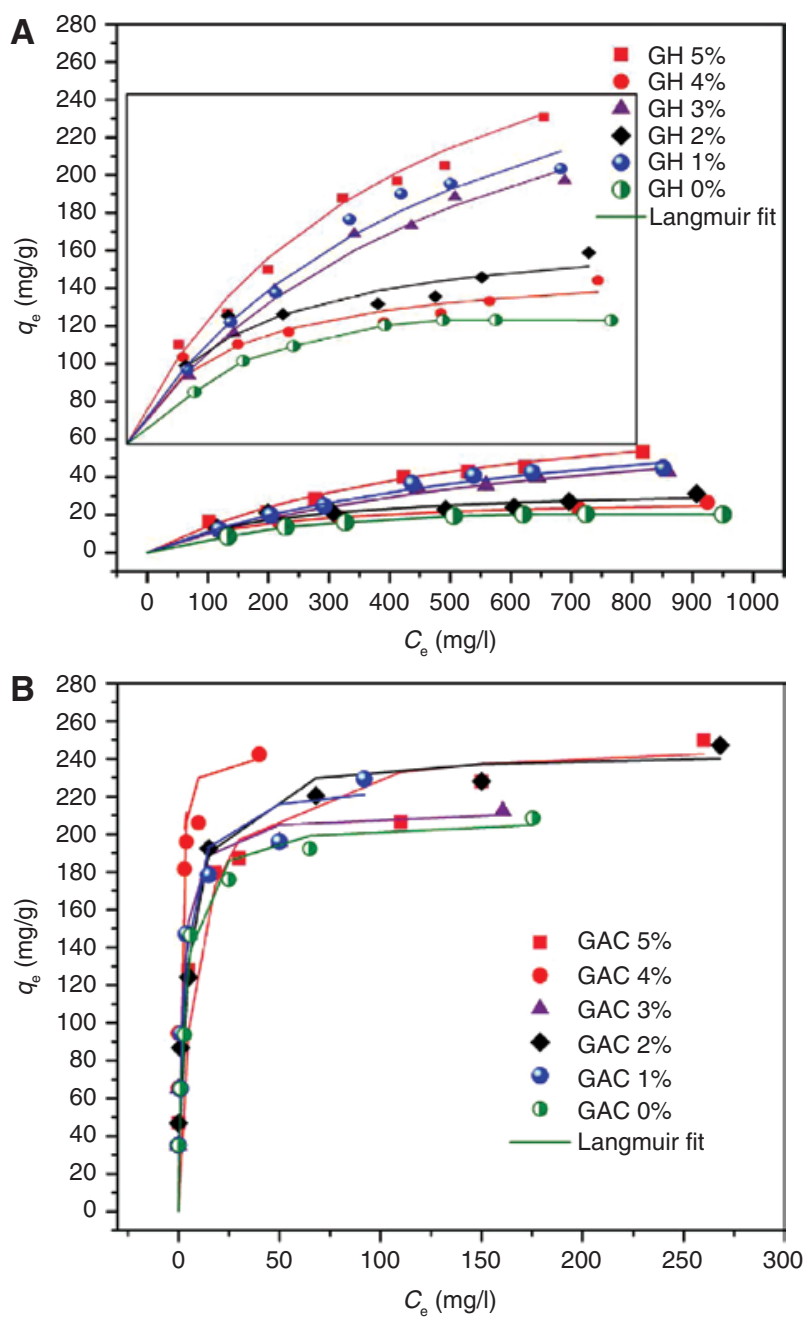

Figure 6: Adsorption isotherms of $\mathrm{Cu}^{2+}$ ions by various (A) glucose hydrochar and (B) activated carbon (AC) samples.

If the oxygen-containing groups on the surface of $\mathrm{GH}_{0 \%}$ $(-\mathrm{COOH}$ and $-\mathrm{OH})$ are assumed to take primary responsibility for binding $\mathrm{Cu}^{2+}$ and $\mathrm{Pb}^{2+}$ ions, the enhanced adsorption capacities of the metal cations for $\mathrm{GH}_{1 \%-5 \%}$ are mainly attributable to the complex reactions between $\mathrm{Cu}^{2+}$ and $\mathrm{Pb}^{2+}$ ions with the amino groups $\left(-\mathrm{NH}_{2}\right)$; other scholars have confirmed this finding $[26,27]$. As expected, the $\mathrm{GH}$ samples exhibited higher adsorption capacities of $\mathrm{Pb}^{2+}$ and $\mathrm{Cu}^{2+}$ than the commercial AC did (Table 2).

The $\mathrm{GAC}_{1 \%-5 \%}$ samples with TETA-modified surfaces possessed higher adsorption capacities toward heavy metals compared with their precursors $\left(\mathrm{GH}_{1 \%-5 \%}\right)$, with increasing ratios of approximately $189-316 \%$ for $\mathrm{Pb}^{2+}$ and $160-720 \%$ for $\mathrm{Cu}^{2+}$ (Table 2). Notably, the adsorption capacity of $\mathrm{GAC}_{0 \%}$ for $\mathrm{Pb}^{2+}$ and $\mathrm{Cu}^{2+}$ was greatly enhanced, compared with that of $\mathrm{GH}_{0 \%}$, increasing to $391 \%$ and $704 \%$, respectively. The result demonstrates that chemical activation with $\mathrm{NaOH}$ can effectively increase the cation exchange capacity. Furthermore, other adsorption mechanisms - complex reactions with oxygen functional groups $(-\mathrm{COOH}$ and $-\mathrm{OH})$ and pore filling - might improve the binding capacities for $\mathrm{GAC}_{\mathrm{x} \%}$ samples.

The $Q^{o}{ }_{\text {max }}$ values of GACs modified with TETA are slightly higher than those without TETA, appropriately 6\%-31\% for $\mathrm{Pb}^{2+}$ and $2 \%-20 \%$ for $\mathrm{Cu}^{2+}$. Therefore, we can conclude that neither amine groups had minor contributions in the adsorption mechanisms of the surface modified GACs samples nor several amine groups might be destroyed during the carbonization at $800^{\circ} \mathrm{C}$. The maximum diminished theoretical adsorption capacities for $\mathrm{Pb}^{2+}$ were ordered as follows: $\mathrm{GAC}_{3 \%}>\mathrm{GAC}_{1 \%}>\mathrm{GAC}_{4 \%}$ $>\mathrm{GAC}_{5 \%}>\mathrm{GAC}_{2 \%}>\mathrm{GAC}_{0 \%}$; by contrast, the ordering of $\mathrm{Cu}^{2+}$ was $\mathrm{GAC}_{5 \%}>\mathrm{GAC}_{4 \%}=\mathrm{GAC}_{2 \%}>\mathrm{GAC}_{1 \%}>\mathrm{GAC}_{3 \%}>\mathrm{GAC}_{0 \%}$.

Generally, the adsorption efficiencies $\left(Q_{\text {max }}^{o} ; \mathrm{mmol} / \mathrm{g}\right)$ of $\mathrm{Cu}^{2+}$ were remarkably higher than those of $\mathrm{Pb}^{2+}$, in both $\mathrm{GH}_{\mathrm{x} \%}$ and $\mathrm{GAC}_{\mathrm{x} \%}$ (Table 2). The adsorption amount order can be explained by the chemical properties of the ions (i.e. hydrated ionic radius, ionic potential, electronegativity, charge density, first hydrolysis equilibrium constant, and ionic radius) [28], which are summarized in Table S1.

As expected, most of the GH and GAC samples that were functionalized with TETA in this study provided greater adsorption capacities for $\mathrm{Cu}^{2+}$ and $\mathrm{Pb}^{2+}$ compared with commercial AC (Table 2) under the same experimental conditions, indicating that TETA is efficient in binding metal cations in the solutions.

\subsubsection{Adsorption isotherms for phenol, MG5, and AR1}

The adsorption isotherms of phenol, MG5, and AR1 on the GH and GAC samples are depicted in Figures 7-9. For the samples modified with TETA $\left(\mathrm{GH}_{1 \%-5 \%}\right.$ and $\left.\mathrm{GAC}_{1 \%-5 \%}\right)$, their adsorption capacities toward phenol, MG5, and AR1 were inversely proportional to the glucose-TETA mass ratios (Table 2). The adsorption capacities of TETA-modified GACs decreased in the following order: $\mathrm{GAC}_{1 \%}>\mathrm{GAC}_{2 \%}>$ $\mathrm{GAC}_{4 \%}>\mathrm{GAC}_{3 \%}>\mathrm{GAC}_{5 \%}$ for phenol, $\mathrm{GAC}_{1 \%}>\mathrm{GAC}_{2 \%}>\mathrm{GAC}_{4 \%}>$ $\mathrm{GAC}_{5 \%}>\mathrm{GAC}_{3 \%}$ for $\mathrm{AR} 1$, and $\mathrm{GAC}_{1 \%}>\mathrm{GAC}_{2 \%}>\mathrm{GAC}_{3 \%}>\mathrm{GA}$ $\mathrm{C}_{4 \%}>\mathrm{GAC}_{5 \%}$ for MG5. A similar decreasing tendency was found in the TETA-modified GH samples.

Several possible mechanisms of the phenol compound adsorption have been postulated in the literature [29-31]: (1) electrostatic attractions, (2) $\pi-\pi$ dispersion interactions, (3) hydrogen bonding, and (4) pore filling.

The mechanisms of electrostatic attractions between the positive protonated amine groups $\left(-\mathrm{NH}_{3}{ }^{+}\right)$on the surface of adsorbents and phenolate anions $\left(\mathrm{C}_{6} \mathrm{H}_{5} \mathrm{O}^{-}\right)$are 
Table 2: Maximum monolayer adsorption capacities $\left(Q_{\max }^{\circ} ; \mathrm{mg} / \mathrm{g}\right)$ of the glucose-derived hydrochar (GH), glucose-activated carbon (GAC) and CAC samples toward $\mathrm{Pb}^{2+}, \mathrm{Cu}^{2+}$, phenol, methylene green 5 (MG5), and acid red 1 (AR1).

\begin{tabular}{lrrrrr}
\hline Adsorbents & Pb(II) & Cu(II) & Phenol & MG5 & AR1 \\
\hline $\mathrm{GH}_{5 \%}$ & $77.5(0.374)$ & $89.3(1.405)$ & $38.2(0.406)$ & $27.5(0.064)$ & $17.0(0.033)$ \\
$\mathrm{GH}_{4 \%}$ & $93.5(0.451)$ & $29.8(0.468)$ & $63.3(0.673)$ & $55.9(0.129)$ & $30.2(0.059)$ \\
$\mathrm{GH}_{3 \%}$ & $115(0.555)$ & $82.0(1.290)$ & $74.6(0.793)$ & $53.5(0.124)$ & $17.6(0.035)$ \\
$\mathrm{GH}_{2 \%}$ & $90.9(0.439)$ & $35.7(0.562)$ & $104(1.107)$ & $58.8(0.136)$ & $33.1(0.065)$ \\
$\mathrm{GH}_{1 \%}$ & $128(0.619)$ & $84.7(1.334)$ & $137(1.456)$ & $67.6(0.156)$ & $36.1(0.071)$ \\
$\mathrm{GH}_{0 \%}$ & $59.9(0.289)$ & $25.9(0.408)$ & $11.4(0.121)$ & $13.9(0.032)$ & $21.2(0.042)$ \\
$\mathrm{GAC}_{5 \%}$ & $323(1.557)$ & $250(3.934)$ & $85.5(0.908)$ & $27.4(0.063)$ & $78.1(0.153)$ \\
$\mathrm{GAC}_{4 \%}$ & $333(1.609)$ & $244(3.838)$ & $101(1.073)$ & $52.9(0.122)$ & $83.3(0.164)$ \\
$\mathrm{GAC}_{3 \%}$ & $385(1.856)$ & $213(3.348)$ & $92.6(0.984)$ & $59.2(0.137)$ & $49.8(0.098)$ \\
$\mathrm{GAC}_{2 \%}$ & $313(1.508)$ & $244(3.838)$ & $139(1.476)$ & $86.2(0.199)$ & $96.2(0.189)$ \\
$\mathrm{GAC}_{1 \%}$ & $370(1.788)$ & $227(3.576)$ & $196(2.084)$ & $101(0.233)$ & $145(0.284)$ \\
$\mathrm{GAC}_{0 \%}$ & $294(1.420)$ & $208(3.278)$ & $122(1.296)$ & $175(0.405)$ & $156(0.307)$ \\
$\mathrm{CAC}^{\mathrm{a}}$ & $25.1(0.121)$ & $20.9(0.252)$ & $219(2.334)$ & $178(0.411)$ & $129(0.250)$ \\
\hline
\end{tabular}

Values in parentheses are presented in $\mathrm{mmol} / \mathrm{g}$.

aThe experimental data were published in [16] with the same operation conditions.

AR1, acid red 1; CAC, commercial activated carbon; GAC, glucose-activated carbon; GH, glucose-derived hydrochar; MG5, methylene green 5.
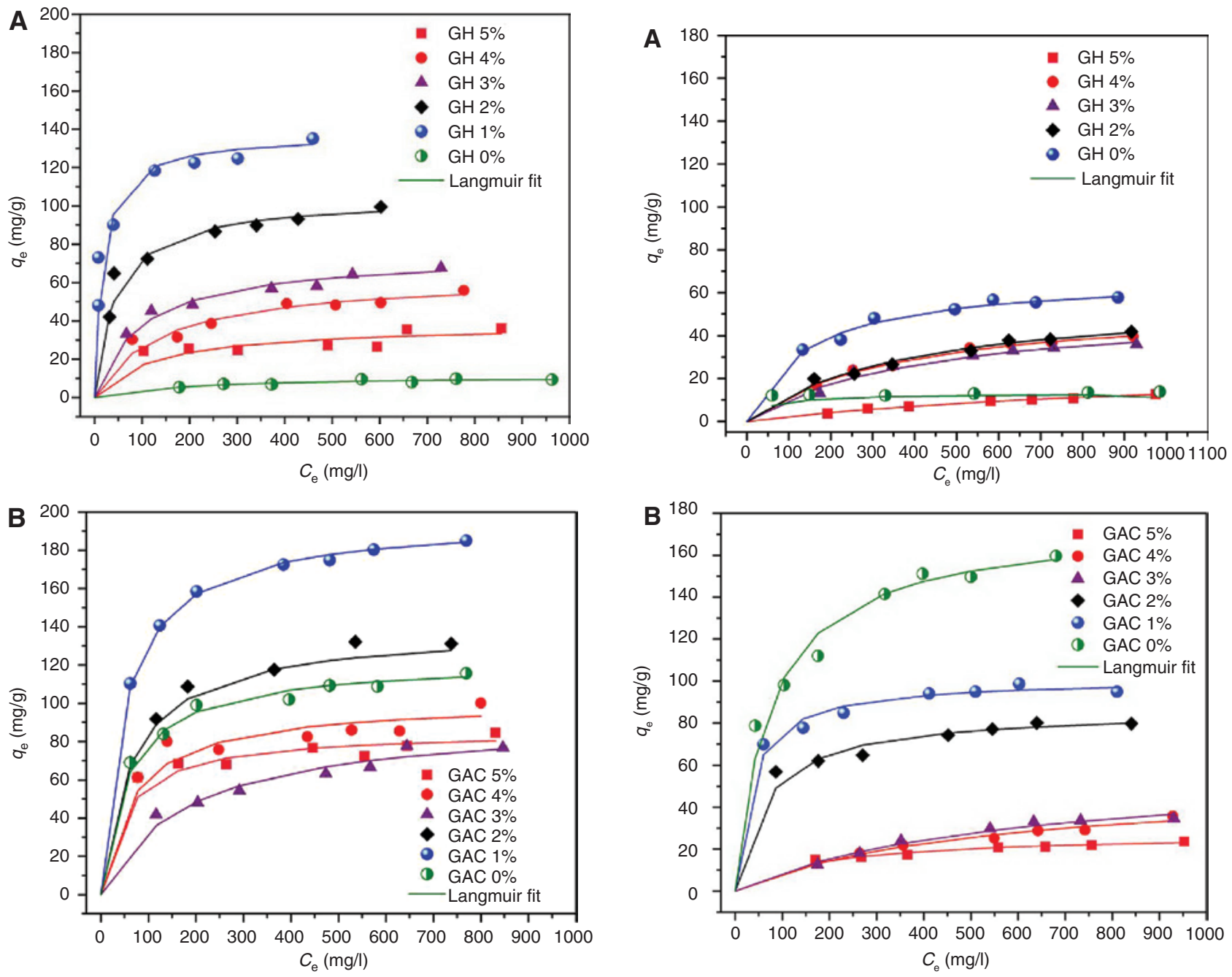

Figure 7: Adsorption isotherms of phenol by various (A) glucose hydrochar and (B) activated carbon (AC) samples.

Figure 8: Adsorption isotherms of methylene green 5 (MG5) by various (A) glucose hydrochar and (B) activated carbon (AC) samples. 

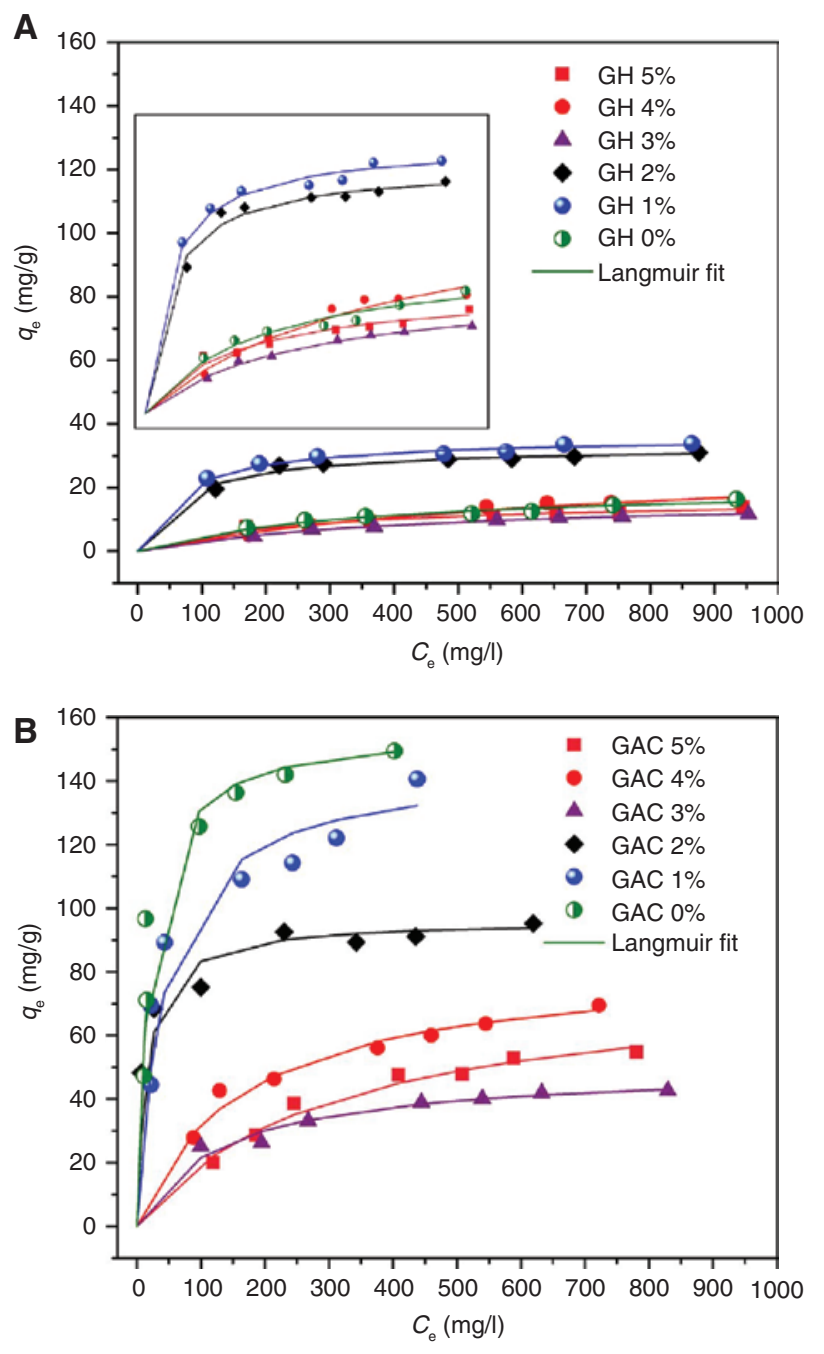

Figure 9: Adsorption isotherms of acid red 1 (AR1) by various (A) glucose hydrochar and (B) activated carbon (AC) samples.

not relevant to this study, and thus are not discussed. This is because the amine groups on the surface of adsorbents can be protonated to $-\mathrm{NH}_{3}{ }^{+}$under an acidic condition (solution $\mathrm{pH}$ controlled at approximately 5.0), but the phenol, a very weak acid, exists primarily in a nondissociated form in water because its $\mathrm{p} K_{a}$ is approximately 9.89 .

Dispersion interactions between the $\pi$-electron in phenol and the $\pi$-electron in carbon can be the dominant mechanism of adsorption in aromatic inorganic compounds. However, the $\pi-\pi$ interaction is greatly affected by the $\pi$-electron density in the basal plane of the carbonous materials. The abundance of oxygen- and nitrogen-containing functional groups (i.e. the electron-withdrawing groups) on the surface of carbonous materials can result in a drop in $\pi$-electron density and adsorption sites in the basal planes (graphene layers) because of $\pi$-electron localization and withdrawal [31]. This explanation is valid for the $\mathrm{GH}_{0 \%}$ sample, which has rich oxygen-bearing groups on its surface and possesses the lowest adsorption capacity (approximately $11 \mathrm{mg} / \mathrm{g}$ ), and is consistent with the findings of other researchers [31-33]. Furthermore, increasing TETA ratios reduces adsorption capacities (Table 2 and Figure 7) because of an overabundance of amino groups linked to a smaller surface, which can weaken the $\pi-\pi$ interactions between the aromatic rings of the adsorbate and the adsorbent matrix [34].

For hydrogen-bonding interactions (i.e. physical adsorption), it is necessary to classify the types of $\mathrm{H}$-bonding formation. First, hydrogen bonding occurs between hydrogen from the hydroxyl group of phenol, and the oxygen complex on the surface of the adsorbent. LorencGrabowska and colleagues [29] proposed that if hydrogen bond formation is the mechanism of phenol adsorption, a strong competition between water and phenol molecules at low phenol concentration leads to reduced adsorption capacity [30]; thus, water molecules are much more competitive in adsorbing on these groups compared with the hydrophobic phenol molecules [35]. However, concave downward adsorption isotherms were obtained for all the GH and GAC samples (Figure 7), indicating only a weak competition between phenol and water adsorption. Therefore, the hydrogen bond interaction in this study is negligible, evidenced in particular by the low adsorption capacity of $\mathrm{GH}_{0 \%}$ (approximately $11 \mathrm{mg} / \mathrm{g}$ ). Second, hydrogen bonding occurs between the nitrogen groups on the adsorbent surface and the hydroxyl group of the phenol; similar results are available in the literature [34]. Additionally, amine groups have a dominant role in the adsorption of phenolic compounds onto amine-modified hyper-crosslinked polymeric resin through hydrogen bonding. This mechanism can explain why the adsorption capacities of $\mathrm{GH}_{1 \%-2 \%}$ and $\mathrm{GAC}_{1 \%-2 \%}$ were higher than $\mathrm{GH}_{0 \%}$ and $\mathrm{GAC}_{0 \%}$ (Table 2 and Figure 7), respectively.

The phenol adsorption capacity of $\mathrm{GAC}_{0 \%}$ (approximately $122 \mathrm{mg} / \mathrm{g}$ ) was extremely higher than that of $\mathrm{GH}_{0 \%}$ because of the pore filling mechanism, indicating that the micropore filling was the other central mechanism of phenol adsorption onto $\mathrm{GAC}_{0 \%}$. Phenol adsorption mainly occurs in micropores smaller than $1.4 \mathrm{~nm}$, and the average pore width of the $\mathrm{GAC}_{0 \%}$ sample in this study was $2.58 \mathrm{~nm}$ (Table 1); an analogous result has been noted in prior studies [16, 29]. Furthermore, nitrogenation introduces nitrogen-containing functional groups onto the carbon surface, such as $-\mathrm{NH}_{2}$, pyridinic, pyrrolic, and quaternary nitrogen groups [14], which enhance the basicity of the carbon surface [36]. Phenols are more strongly removed from a solution by a basic carbon than an acidic carbon [37]; therefore, the samples functionalized with TETA 
always exhibited higher adsorption capacities than did those without TETA (Table 2 and Figure 7).

The adsorption capacity of MG5 onto $\mathrm{GAC}_{0 \%}$ (approximately $157 \mathrm{mg} / \mathrm{g}$ ) was higher than that of $\mathrm{GAC}_{1 \%-5 \%}$ (approximately $27.4-101 \mathrm{mg} / \mathrm{g}$ ), which might be attributed to the higher cation exchange of $\mathrm{GAC}_{0 \%}$ than $\mathrm{GAC}_{1 \%-5 \%}$; this coincides with the higher Na content on the $\mathrm{GAC}_{0 \%}(5.61 \%)$ than $\mathrm{GAC}_{10 \%}(3.80 \%)$ surfaces. As Romero and others [19] reported, ion exchange plays a critical role in the adsorption of MG1 onto NaOH-AC spheres with abundant surfacegrafted functional groups.

The adsorption capacity of $\mathrm{GAC}_{0 \%}(175 \mathrm{mg} / \mathrm{g})$ for MG5 was nearly the same as that of commercial AC $(178 \mathrm{mg} / \mathrm{g}$ ) under the same experimental conditions; as Figure S5 illustrates, this study similarly found an excellent relationship between the maximum adsorption capacity $\left(Q^{\circ}{ }_{\max }\right)$ of MG5 by GACs and non-micropore surface area $\left(R^{2}=0.97\right)$ and nonmicropore volume $\left(R^{2}=0.96\right)$. These correlated values demonstrate that the adsorption of MG5 by GACs was governed by non-micropore filling.

The maximum adsorption capacities of the TETAmodified hydrochar samples were nearly equal to those of the AC samples with TETA: $\mathrm{GH}_{5 \%}(27.5 \mathrm{mg} / \mathrm{g}) \approx \mathrm{GAC}_{5 \%}$ $(27.4 \mathrm{mg} / \mathrm{g}), \mathrm{GH}_{4 \%}(55.9 \mathrm{mg} / \mathrm{g}) \approx \mathrm{GAC}_{4 \%}(52.9 \mathrm{mg} / \mathrm{g})$, and $\mathrm{GH}_{3 \%}(53.5 \mathrm{mg} / \mathrm{g}) \approx \mathrm{GAC}_{2 \%}(59.2 \mathrm{mg} / \mathrm{g})$. This result indicates that TETA has a positive effect on the adsorption enhancement of MG5.

Clearly, the affinities of the GH samples toward AR1 were lower than those toward phenol and MG5, because the negative charge for AR1 can generate the repulsion forces of the functional groups (i.e. $-\mathrm{COO}^{-}$) on the hydrochar surface. If the amine groups $\left(-\mathrm{NH}_{2}\right)$ on the hydrochar samples with TETA are completely protonated to $-\mathrm{NH}_{3}{ }^{+}$under an acidic condition ( $\mathrm{pH}=$ approximately 5.0), then the adsorption capacity of the hydrochar samples with TETA are enhanced because of electrostatic attraction. In this study, however, the amine groups $\left(-\mathrm{NH}_{2}\right)$ on the TETA-modified hydrochar samples were not protonated to $-\mathrm{NH}_{3}{ }^{+}$in the solution; therefore, the adsorption mechanisms of AR1 onto the hydrochar sample with TETA did not involve the amine groups through an anion exchange process, and the hydrogen bonding interactions between the nitrogenand oxygen-containing functional groups on the dye molecule and the adsorbents' surface might be responsible for the adsorption mechanisms [38, 39]. Similar to the adsorption of MG5, $\mathrm{GAC}_{0 \%}$ (approximately $156 \mathrm{mg} / \mathrm{g}$ ) also exhibited a higher affinity toward AR1 than $\mathrm{GAC}_{1 \%-5 \%}$ (approximately 49-145 $\mathrm{mg} / \mathrm{g}$ ); moreover, the adsorption of AR1 by the $\mathrm{GAC}_{0 \%}(156 \mathrm{mg} / \mathrm{g})$ and $\mathrm{GAC}_{1 \%}$ (145 mg/g) samples was higher than that of commercial
AC $(129 \mathrm{mg} / \mathrm{g})$, indicating that $\mathrm{GAC}_{1 \%}$ became an excellent adsorbent.

\section{Conclusions}

Synthesizing hydrochar and AC with a TETA-glucose mixture substantially changes the morphology of the modified hydrochar samples. Specifically, increasing TETA concentrations leads to a diminished surface area $\left(S_{\mathrm{BET}}\right)$, non-micropore volume, and total pore volume in glucose ACs, and an increased micropore volume.

The adsorption capacities of the GH samples toward inorganic and organic compounds were considerably enhanced with TETA modification. Specifically, increasing TETA concentrations resulted in decreased adsorption capacities for the compound contaminants, with the $\mathrm{GH}_{1 \%}$ sample exhibiting the highest affinity toward the contaminants. The maximum adsorption capacities $\left(Q^{\circ}{ }_{\max }\right)$ of $\mathrm{GH}_{1 \%}$ were ordered as follows: phenol $(1.456 \mathrm{mmol} / \mathrm{g})>\mathrm{Cu}^{2+}$ $\left(\begin{array}{ll}1.334 \mathrm{mmol} / \mathrm{g}\end{array}\right)>\mathrm{Pb}^{2+} \quad(0.619 \quad \mathrm{mmol} / \mathrm{g})>\mathrm{MG} 1$ $(0.156 \mathrm{mmol} / \mathrm{g})>$ AR1 $(0.071 \mathrm{mmol} / \mathrm{g})$.

The GAC samples exhibited even higher adsorption capacities than did their GH precursors and the commercial $\mathrm{AC}$, with $\mathrm{GAC}_{1 \%}$ reaching the highest adsorption capacity for most of the contaminants. The $Q^{\circ}{ }_{\max }$ values of $\mathrm{GAC}_{1 \%}$ for the contaminants were ordered as follows: $\mathrm{Cu}^{2+}(3.576 \mathrm{mmol} / \mathrm{g})>$ phenol $(2.084 \mathrm{mmol} / \mathrm{g})>\mathrm{Pb}^{2+}$ $\left(\begin{array}{ll}1.788 \quad \mathrm{mmol} / \mathrm{g}\end{array}\right)>$ AR1 $\quad(0.284 \quad \mathrm{mmol} / \mathrm{g})>\mathrm{MG} 1$ $(0.233 \mathrm{mmol} / \mathrm{g})$. These values are notably higher than the corresponding values of commercial AC.

Acknowledgments: This work was financially supported by Chung Yuan Christian University (CYCU), Taiwan. The first author would like to thank CYCU for the Distinguished International Graduate Students (DIGS) scholarship to pursue his doctoral studies.

Conflict of interest statement: The authors declare that no competing financial or other conflicts exist.

\section{References}

[1] Freedonia, World activated carbon - industry market research, market share, market size, sales, demand forecast, market leaders, company profiles, industry trends. Industry Studies and Freedonia Focus Report, 2014.

[2] Romero-Anaya AJ, Ouzzine M, Lillo-Ródenas MA, Linares-Solano A. Carbon 2014, 68, 296-307.

[3] Jain A, Balasubramanian R, Srinivasan MP. Chem. Eng. J. 2016, 283, 789-805. 
[4] Titirici MM, White RJ, Falco C, Sevilla M. Energy. Environ. Sci. 2012, 5, 6796-6822.

[5] Bedin KC, Martins AC, Cazetta AL, Pezoti O, Almeida VC. Chem. Eng. J. 2016, 286, 476-484.

[6] Mwenya T, Fan H, Dai H, Li M. Int. J. Photoenergy 2016, 2016, 1-5.

[7] Demir-Cakan R, Baccile N, Antonietti M, Titirici M-M. Chem. Mater. 2009, 21, 484-490.

[8] Wang X, Liu J, Xu W. Colloids Surf. A 2012, 415, 288-294.

[9] Chizari K, Vena A, Laurentius L, Sundararaj U. Carbon 2014, 68, 369-379.

[10] Karnitz Jr O, Gurgel LV, de Melo JC, Botaro VR, Melo TM, de Freitas Gil RP, Gil LF. Bioresour. Technol. 2007, 98, 1291-1297.

[11] Niasar HS, Li H, Kasanneni TVR, Ray MB, Xu C. Chem. Eng. J. 2016, 293, 189-199.

[12] Gurgel LVA, Gil LF. Water Res. 2009, 43, 4479-4488.

[13] Gurgel LVA, Gil LF. Carbohydr. Polym. 2009, 77, 142-149.

[14] Barsanescu A, Buhaceanu R, Dulman V, Bunia I, Neagu V. J. Appl. Polym. Sci. 2004, 93, 803-808.

[15] Sing KS. Pure Appl. Chem. 1985, 57, 603-619.

[16] Huang FC, Lee C-K, Han Y-L, Chao W-C, Chao H-P. J. Taiwan Inst. Chem. Eng. 2014, 45, 2805-2812.

[17] Sevilla M, Fuertes AB. Chem. Eur. J. 2009, 15, 4195-4203.

[18] Sevilla M, Fuertes AB. Carbon 2009, 47, 2281-2289.

[19] Romero VJM, Tsai JF, Doma Jr, BT, Chao HP. Sustain. Environ. Res. 2014, 24, 339-347.

[20] Song X, Gunawan P, Jiang R, Leong SS, Wang K, Xu R. J. Hazard. Mater. 2011, 194, 162-168.

[21] Lai L, Huang G, Wang X, Weng J. Carbon 2010, 48, 3145-3156.

[22] Salehi E, Madaeni SS, Rajabi L, Vatanpour V, Derakhshan AA, Zinadini S, Ghorabi S, Ahmadi Monfared H. Sep. Purif. Technol. 2012, 89, 309-319.

[23] Zhu J, Yang J, Deng B. J. Hazard. Mater. 2009, 166, 866-872.

[24] Brady D, Duncan JR. Enzyme Microb. Technol. 1994, 16, 633-638.

[25] Tran HN, You SJ, Chao HP. Waste Manage. Res. 2016, 34, 129-138.

[26] Chand P, Shil AK, Sharma M, Pakade YB. Int. Biodeterior. Biodegrad. 2014, 90, 8-16.

[27] Xiao B, Thomas KM. Langmuir 2005, 21, 3892-3902.

[28] Petrov N, Budinova T, Khavesov I. Carbon 1992, 30, 135-139.

[29] Lorenc-Grabowska E, Gryglewicz G, Diez MA. Fuel 2013, 114, 235-243.

[30] Moreno-Castilla C. Carbon 2004, 42, 83-94.

[31] Radovic LR, Baker FS. Carbon 1997, 35, 1339-1348.

[32] Mahajan OP, Moreno-castilla C, Walker PL. Sep. Sci. Technol. 1980, 15, 1733-1752.

[33] Salame II, Bandosz TJ. J. Colloid Interface Sci. 2003, 264, 307-312.

[34] Li A, Zhang Q, Wu H, Zhai Z, Liu F, Fei Z, Long C, Zhu Z, Chen J. Adsorp. Sci. Technol. 2004, 22, 807-819.

[35] Franz M, Arafat HA, Pinto NG. Carbon 2000, 38, 1807-1819.

[36] Yang G, Chen H, Qin H, Feng Y. Appl. Surf. Sci. 2014, 293, 299-305.

[37] Terzyk AP. J. Colloid Interface Sci. 2003, 268, 301-329.

[38] Li M, Wang H, Wu S, Li F, Zhi P. RSC Adv 2012, 2, 900-907.

[39] Ahmad R, Kumar R. J. Chem. Eng. Data 2010, 55, 3489-3493.

Supplemental Material: The online version of this article (DOI: 10.1515/gps-2016-0178) offers supplementary material, available to authorized users.

\section{Bionotes}

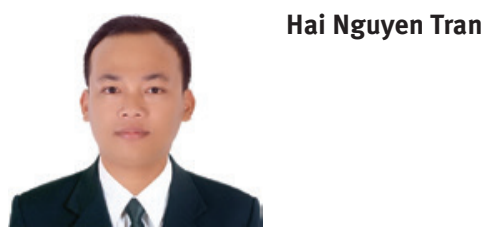

Hai Nguyen Tran is currently a PhD student at the Environmental Engineering Department, Chung Yuan Christian University, Taiwan. His recent publications focused on (1) the removal of cadmium from aqueous solutions using orange peel-derived biochar produced from different pyrolysis temperatures and times, (2) comparison of the calculation results of the thermodynamic parameters in the adsorption study by different methods, (3) preparation and characterization of various adsorbents (i.e. biosorbent, hydrochar, biochar, spherical carbon, activated carbon, surfactant modified zeolite, and Mg-Al LDHs intercalated with phenylalanine, tyrosine, and serine) for the removal of organic and inorganic contaminants from aqueous solutions, (4) preparation of activated carbon from a new chemical activation method. https://www.researchgate.net/ profile/Hai_Tran16.

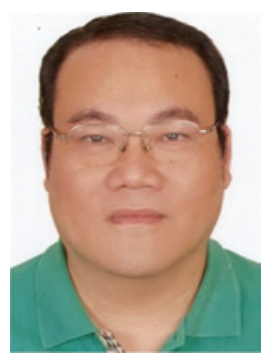

\section{Fu-Chuang Huang}

Fu-Chuang Huang completed his PhD in Environmental Engineering at National Central University, Chung-Li, Taiwan. Currently, he is a faculty member at Nanya Institute of Technology, Chung-Li, Taiwan. His research interests are in soil pollution remediation, adsorption, wastewater treatment, and environmental education.

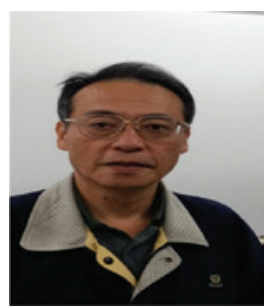

Chung-Kung Lee

Chung-Kung Lee completed his PhD in Chemical Engineering at National Central University, Chung-Li, Taiwan. He has published more than 65 research articles as first and co-author in $\mathrm{SCl}$ journals. He received his BSc in Chemical Engineering from Taipei Institute of Technology, Taipei, Taiwan and his MSc in Chemical Engineering from National Central University, Chung-Li, Taiwan. Currently, he is a faculty member at University of Vanung, Chung-Li, Taiwan. His research interests are in fractal and chaos analysis, adsorption, catalysis and wastewater treatment. https://www.researchgate.net/ profile/Chung_Kung_Lee. 


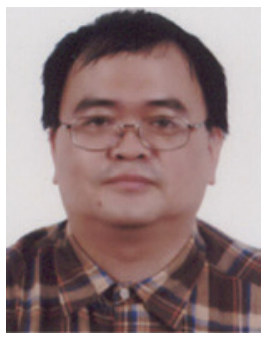

Huan-Ping Chao

Huan-Ping Chao completed his PhD in Graduate Institute of Environmental Engineering, National Central University, Chung-Li, Taiwan. He has published more than 35 research articles as first and co-author in $\mathrm{SCl}$ journals. Currently, he is a faculty member at Department of Environmental Engineering, Chung Yuan Christian University, Chung-Li, Taiwan. His research interests are in volatilization of organic compounds from water, and development of new adsorbents to remove contaminants in wastewater. https://www. researchgate.net/profile/Huan-Ping_Chao. 